\title{
RESEARCH ON AIRFREIGHT LOADING OPTIMIZATION OF E-COMMERCE LOGISTICS BASED ON IMPROVED GENETIC ALGORITHM
}

\author{
Jing Zhang \\ Changsha Aeronautical Vocational and Technical College, Changsha, Hunan 410124, China \\ Email: jingzzhangj@yeah.net
}

\begin{abstract}
At present, more and more e-commerce logistics use airfreight. To further optimize the freight loading problem, this study first established the freight loading optimization model, improved the genetic algorithm to solve the model, and made an example analysis. It was found that the load utilization rate was $96.63 \%$, and the space utilization rate was $92.95 \%$ in the scheme obtained by the algorithm proposed in this study, which was higher than those of the other two algorithms. In the aspect of calculation time, the method proposed in this study could obtain the optimal scheme in $56.78 \mathrm{~s}$. The experimental results show that the proposed algorithm performs better in the loading optimization problem and can be further promoted and applied.
\end{abstract}

Keywords: Genetic Algorithm, E-Commerce Logistics, Air Logistics, Loading Optimization.

\section{Introduction}

With the development of economy and network, e-commerce enterprises have also been booming, and their distribution area is no longer limited to the domestic but over the world. At present, the logistics modes of e-commerce include waterway, land, and air, and airfreight is fast and efficient, which is favored by more and more e-commerce enterprises. Airfreight plays a very important role in the global transportation industry $[1,2]$. In airfreight, it is first necessary to place the cargo on the aircraft. If the loading is unreasonable, it will cause a waste of space [3], which is not conducive to cost control [4]. Therefore, how to realize the optimization of freight loading has become an important issue in aviation logistics. Peng et al. [5] analyzed the airfreight data of the first three months of 2018 and designed a multi-programming-based air cargo redistribution model that could effectively balance the cargo utilization of flights. Considering the fragility and weight distribution of items, Paquay et al. [6] proposed a mixed-integer linear program to solve the packing problem and verified its effectiveness by testing on a small example. Roesener et al. [7] analyzed the cargo loading problem and developed an advanced tabu search method to solve the combination problem considering factors such as cabin load, balance, and time constraints. Nance et al. [8] designed a two-dimensional bin packing algorithm based on tabu search, compared it with other algorithms, and found that the algorithm needed fewer aircraft to complete the loading task, although it took more time. In this study, the freight loading optimization model was established, the genetic algorithm was improved to solve the problem, and the example analysis also verified the effectiveness of the method. The present study contributes to realizing the freight loading optimization and improving the efficiency of ecommerce logistics.

\section{Airfreight Loading Model}

\subsection{Airfreight Loading Problem}

The center of gravity determines the flight stability of the aircraft and has an impact on fuel consumption [9]. Therefore, in cargo loading, it is necessary to ensure the center of gravity position of the aircraft, and the solution formula is:

$$
C=\frac{\sum_{i} M_{i}}{\sum_{i} F_{i}}
$$

where $M_{i}$ refers to the moment of a unit load device (ULD) [10] and $F_{i}$ refers to the gravity of a ULD. In the practical calculation, the center of gravity is expressed as:

$$
C_{\% M A C}=\frac{C-L E M A C}{M A C} \times 100 \%
$$

where $M A C$ refers to the average aerodynamic chord length of the aircraft and LEMAC refers to the distance from the reference point to the leading 
edge of the average aerodynamic chord. The above two values are given by the aircraft manufacturer.

At present, in e-commerce logistics, the services provided by airlines can be divided into two types:

(1) Loading by the belly of passenger aircraft: it refers to carry cargo with ordinary passenger aircraft. The main cabin of the aircraft is used for carrying passengers, and the belly is used for carrying cargo. The flight and route are fixed, and the carrying capacity is large. There are many requirements for the size of the cargo.

(2) Loading by all-cargo aircraft: it refers to carry cargo with the aircraft whose cabins are all used for loading cargo. This kind of aircraft has a very large cargo capacity and has no large restriction on the size of the goods; therefore, it has a wide prospect in e-commerce logistics. Therefore, this study mainly analyzed loading by all-cargo aircraft.

\subsection{Model Assumptions}

To facilitate the calculation, it is necessary to make some assumptions before the model is established:

(1) the loading space is a regular rectangle;

(2) the goods are rectangular;

(3) the center of gravity of the goods is its geometric center;

(4) the influence of bulk cargo on the center of gravity is ignored;

(5) the goods can be placed at will;

(6) the influences of fuel weight and temperature are ignored;

(7) the goods are sent to the same destination without unloading halfway.

\section{Modeling}

In the process of modeling, some parameters needed are shown in Table 1.

Table 1. Model Parameters

\begin{tabular}{|c|c|}
\hline Parameter & Meaning \\
\hline$B$ & ULD type, $B=1,2, \ldots, h$ \\
\hline$N_{B}$ & $\begin{array}{l}\text { The maximum available quantity } \\
\text { of type B ULD }\end{array}$ \\
\hline$X_{B}$ & $\begin{array}{l}\text { The actual quantity of type B ULD } \\
\text { used }\end{array}$ \\
\hline$M_{B}$ & $\begin{array}{l}\text { The maximum carrying capacity } \\
\text { of type B ULD }\end{array}$ \\
\hline$G_{B}$ & Weight of type B ULD \\
\hline$V_{B}$ & $\begin{array}{l}\text { The maximum volume of type B } \\
\text { ULD, } V_{B}=L_{B} W_{B} H_{B}\end{array}$ \\
\hline$L_{B}$ & Length of type B ULD \\
\hline$W_{B}$ & Width of type B ULD \\
\hline$H_{B}$ & Height of type B ULD \\
\hline$l_{i}$ & Length of the $i_{\text {-th cargo, }}$ \\
\hline
\end{tabular}

\begin{tabular}{|c|c|}
\hline & $i=1,2, . ., n$ \\
\hline$w_{i}$ & Width of the ${ }^{i}$-th cargo \\
\hline$h_{i}$ & Height of the $i$-th cargo \\
\hline$M_{i}$ & Mass of the ${ }^{i}$-th cargo \\
\hline$V_{i}$ & $\begin{array}{l}\text { Volume of the }{ }^{i} \text {-th cargo, } \\
V_{i}=l_{i} w_{i} h_{i}\end{array}$ \\
\hline$V_{m}$ & $\begin{array}{l}\text { The maximum loading volume of } \\
\text { the cargo hold }\end{array}$ \\
\hline$M_{m}$ & $\begin{array}{l}\text { The maximum carrying capacity } \\
\text { of cargo aircraft }\end{array}$ \\
\hline$M_{e m p}$ & The empty weight of cargo craft \\
\hline$\left(x_{0}, y_{0}, z_{0}\right)$ & $\begin{array}{l}\text { The initial center-of-gravity } \\
\text { coordinates of cargo aircraft }\end{array}$ \\
\hline$\left(x_{i}, y_{i}, z_{i}\right)$ & $\begin{array}{l}\text { The center-of-gravity coordinates } \\
\text { of the } i \text {-th cargo }\end{array}$ \\
\hline$\left(\varphi_{x}, \varphi_{y}, \varphi_{z}\right)$ & $\begin{array}{l}\text { The center-of-gravity coordinates } \\
\text { of cargo aircraft after loading } \\
\text { with cargo } i\end{array}$ \\
\hline $\left.\mid x_{\text {down }}, x_{\text {up }}\right\rfloor$ & $\begin{array}{l}\text { The center-of-gravity range in the } \\
\text { direction of the length of cargo } \\
\text { aircraft }\end{array}$ \\
\hline$\left[y_{\text {down }}, y_{\text {up }}\right.$ & $\begin{array}{l}\text { The center-of-gravity range in the } \\
\text { direction of the width of cargo } \\
\text { aircraft }\end{array}$ \\
\hline $\mid O, z_{u p}$ & $\begin{array}{l}\text { The center-of-gravity range in the } \\
\text { direction of the height of cargo } \\
\text { aircraft }\end{array}$ \\
\hline$\left[s_{\text {down }}, s_{\text {up }}\right]$ & $\begin{array}{l}\text { Range of the security coefficient } \\
\text { of center-of-gravity }\end{array}$ \\
\hline
\end{tabular}

The objective function of the model is written as:

$$
\max Z=\gamma \sum_{B=1}^{h} X_{B}\left(\sum_{i=1}^{n} \frac{M_{i} \delta_{i}^{B}}{M_{B}}\right)+(1-\gamma) \sum_{B=1}^{h} X_{B}\left(\sum_{i=1}^{n} \frac{V_{i} \delta_{i}^{B}}{V_{B}}\right)
$$

The constraints of the model is written as:

$$
\begin{aligned}
& \sum_{i=1}^{n} M_{i}+\sum_{B=1}^{h} G_{B} X_{B} \leq M_{m} \\
& \sum_{B=1}^{h} V_{B} X_{B} \leq V_{m} \\
& \sum_{B=1}^{h} \sum_{i=1}^{n} M_{i} \delta_{i}^{B} \leq \sum_{B=1}^{h} M_{B} X_{B} \\
& \sum_{B=1}^{h} \sum_{i=1}^{n} V_{i} \delta_{i}^{B} \leq \sum_{B=1}^{h} V_{B} X_{B} \\
& X_{B} \leq N_{B} \\
& \sum_{B=1}^{h} \delta_{i}^{B}=1
\end{aligned}
$$




$$
\begin{aligned}
& \varphi_{x}=\frac{M_{e m p} x_{u p}+\sum_{B=1}^{h} \sum_{i=1}^{n} M_{i} \delta_{i}^{B} x_{i}^{B}}{M_{e m p}+\sum_{B=1}^{h} \sum_{i=1}^{n} M_{i} \delta_{i}^{B}} \\
& \varphi_{y}=\frac{M_{\text {emp }} y_{\text {up }}+\sum_{B=1}^{h} \sum_{i=1}^{n} M_{i} \delta_{i}^{B} x_{i}^{B}}{M_{\text {emp }}+\sum_{B=1}^{h} \sum_{i=1}^{n} M_{i} \delta_{i}^{B}}
\end{aligned}
$$

\section{Solution by Improved Genetic Algorithm}$$
\varphi_{z}=\frac{M_{\text {emp }} z_{u p}+\sum_{B=1}^{h} \sum_{i=1}^{n} M_{i} \delta_{i}^{B} x_{i}^{B}}{M_{e m p}+\sum_{B=1}^{h} \sum_{i=1}^{n} M_{i} \delta_{i}^{B}}
$$$$
x_{\text {down }} \leq \varphi_{x} \leq x_{\text {up }}
$$$$
y_{\text {down }} \leq \varphi_{y} \leq y_{\text {up }}
$$$$
O \leq \varphi_{z} \leq z_{u p}
$$$$
s_{\text {down }}<r_{1} \varphi_{z} \cdot\left|\varphi_{x}-x_{\text {emp }}\right|<s_{u p}
$$$$
s_{\text {down }}<r_{2} \varphi_{z} \cdot\left|\varphi_{y}-y_{\text {emp }}\right|<s_{\text {up }}
$$$$
x_{i}^{B}=\frac{\sum_{i=1}^{n} M_{i} l_{i}}{\sum_{i=1}^{n} M_{i}}
$$$$
y_{i}^{B}=\frac{\sum_{i=1}^{n} M_{i} w_{i}}{\sum_{i=1}^{n} M_{i}}
$$$$
z_{i}^{B}=\frac{\sum_{i=1}^{n} M_{i} h_{i}}{\sum_{i=1}^{n} M_{i}}
$$

The meaning of the constraints is as follows:

- equation (4): the total weight of cargo shall not exceed the maximum carrying capacity of cargo aircraft;

- equation (5): the total volume of cargo shall not exceed the maximum loading volume of cargo hold;

- equation (6): the total weight of cargo in a single ULD shall not exceed its maximum carrying capacity;

- equation (7): the total volume of cargo in a single ULD shall not exceed its maximum volume;

- equation (8): the actual number of ULDs used shall not exceed its maximum available quantity;

- equation (9): cargo can only be loaded into one ULD;

- equation (10) - (12): the center-of-gravity coordinates of cargo aircraft after loading cargo;

- equation (13) - (15): the center-of-gravity constraints of cargo aircraft;

The loading optimization problem is an NP-hard problem [11], which is difficult to solve. In this study, the model was solved by the improved genetic algorithm. The genetic algorithm has good applicability in solving optimization problems; therefore, it has good applications in fields such as machinery and electrical engineering [12, 13]. Its basic flow is shown in Figure 1.

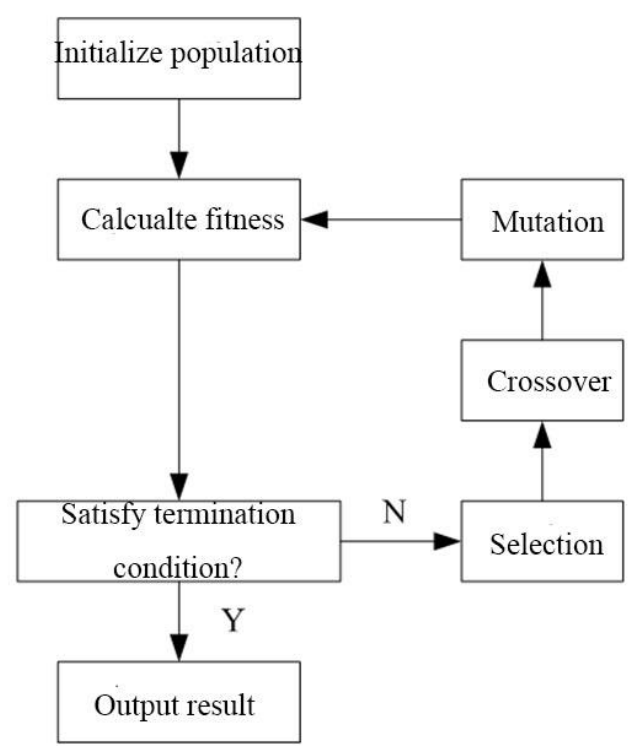

Figure 1: The Flow of the Genetic Algorithm

Although the genetic algorithm has many advantages, it also has some problems, such as easy to fall into the local extremum and low convergence speed. Different steps of the algorithm are improved to get a better performance in cargo loading optimization.

First of all, in the coding part, this study adopted digital coding rather than conventional binary coding.

Suppose there are $n$ ULDs, numbered as $0 \sim n-1$, and the length of the chromosome is represented by $m$. If there are 10 ULDs, numbered as $0 \sim 9$, and eight freight spaces, then eight numbers are randomly selected from $0 \sim 9$ as one solution, i.e., a chromosome, for example, chromosome $(3,1,4,6,8$, $7,5,2)$, which represents the placement order of ULD.

In operator selection, the roulette method is adopted in this study. 
After calculating the fitness sum of the whole population, the probability that each chromosome can be inherited to the next generation is calculated. If the population size is $N$ and the fitness of chromosome $i$ is $f_{i}$, then the probability that $i$ will be selected is:

$$
\rho_{i}=\frac{f_{i}}{\sum_{i=1}^{N} f_{i}}
$$

Finally, through the roulette operation, the number of times each chromosome is selected is determined using the random number in $[0,1]$.

In the aspect of the crossover operator, the partially matched crossover (PMX) method is used. For a pair of chromosomes, several genes are randomly selected:
A: 234567891,
B: 657132894

The location of the genes is exchanged:

$$
\begin{aligned}
& \text { A: } 237132891 \text {, } \\
& \text { B: } 654567894 .
\end{aligned}
$$

Conflict detection: according to the exchange results, it is found that there are two " 1 " in A and two " 5 " in B, i.e., two ULDs that are numbered as one are placed at freight space 4 and 9 respectively in loading scheme A, and two ULDs that are numbered as five are placed at freight space 2 and 4 , which does not conform to the rule that one ULD can only be placed in one freight space. Therefore, transform is needed through mapping relationships to ensure that the genes have no conflict. The final results are as follows:

A: 467132785
To preserve the excellent chromosome in the mutation operator, inversion mutation is used. For a chromosome,

\section{9 ,}

the genes between 5 and 7 are inverted completely, then

214763589.

After the above operation, when the set number of iterations is reached, the algorithm ends, and the output result is the optimal solution of the loading optimization model.

\section{Example Analysis}

It was assumed that an e-commerce company had 40 pieces of goods to be transported, and the specifications of the goods are shown in Table 2.

Table 2. Cargo Specifications

\begin{tabular}{|l|l|l|l|l|}
\hline Number & $\begin{array}{l}\text { Length/ } \\
\mathrm{m}\end{array}$ & $\begin{array}{l}\text { Width/ } \\
\mathrm{m}\end{array}$ & $\begin{array}{l}\text { Height/ } \\
\mathrm{m}\end{array}$ & $\begin{array}{l}\text { Weight/ } \\
\mathrm{t}\end{array}$ \\
\hline $1-6$ & 290 & 80 & 90 & 3.8 \\
\hline $7-10$ & 480 & 90 & 100 & 4.2 \\
\hline $11-14$ & 100 & 100 & 100 & 0.8 \\
\hline $15-18$ & 300 & 80 & 200 & 1.3 \\
\hline $19-25$ & 280 & 200 & 120 & 4.8 \\
\hline $26-31$ & 170 & 170 & 100 & 1.5 \\
\hline $32-40$ & 180 & 170 & 100 & 2.6 \\
\hline
\end{tabular}

The maximum carrying capacity of the cargo aircraft used was $110468 \mathrm{~kg}$. The ULD used had two types, A and B. The parameters of the model are shown in Table 3.

Table 3. Specific Parameters of the Model

\begin{tabular}{|l|l|l|}
\hline Parameter & Numerical value \\
\hline$B$ & 2 & \multicolumn{2}{l|}{} \\
\hline Type of ULD & A & B \\
\hline$N_{B}$ & 1 & 3 \\
\hline$M_{B}$ & $6804 \mathrm{~kg}$ & $1588 \mathrm{~kg}$ \\
\hline$G_{B}$ & $110 \mathrm{~kg}$ & $125 \mathrm{~kg}$ \\
\hline$V_{B}$ & $11.6 \mathrm{~m}^{3}$ & $3.9 \mathrm{~m}^{3}$ \\
\hline$L_{B}$ & $318 \mathrm{~cm}^{2}$ & $156 \mathrm{~cm}$ \\
\hline$W_{B}$ & $224 \mathrm{~cm}$ & $153 \mathrm{~cm}$ \\
\hline$H_{B}$ & $163 \mathrm{~cm}$ & $163 \mathrm{~cm}$ \\
\hline$V_{m}$ & $675 \mathrm{~m}^{3}$ \\
\hline$M_{m}$ & $100 \mathrm{t}$ \\
\hline$M_{e m p}$ & $181 \mathrm{t}$ \\
\hline$\left(x_{0}, y_{0}, z_{0}\right)$ & {$[2560,244,150)$} \\
\hline$\left.x_{\text {down }}, x_{u p}\right\rfloor$ & {$[0 \sim 20 \mathrm{~cm}]$} \\
\hline$\left.y_{\text {down }}, y_{u p}\right\rfloor$ & {$[0 \sim 20 \mathrm{~cm}]$} \\
\hline$\left[O, z_{u p}\right\rfloor$ & {$[0 \sim 10 \mathrm{~cm}]$} \\
\hline$\left.S_{\text {down }}, S_{u p}\right\rfloor$ & $20 \% \sim 40 \% \mathrm{ba}$ \\
\hline
\end{tabular}


It was assumed that the population size of the improved genetic algorithm was 150, the maximum number of iterations was 1000 , and the mutation probability was 0.1 . The loading optimization model was solved, and the loading scheme obtained is shown in Table 4.

Table 4. Loading Scheme

\begin{tabular}{|l|l|l|}
\hline Goods No. & $\begin{array}{l}\text { Number of } \\
\text { loading layers }\end{array}$ & $\begin{array}{l}\text { Placement } \\
\text { direction }\end{array}$ \\
\hline ULD A & 1 & 1 \\
\hline $1-3$ & 2 & 1 \\
\hline $7-8$ & 3 & 4 \\
\hline $15-16$ & 4 & 1 \\
\hline $32-37$ & \multicolumn{2}{|l|}{} \\
\hline ULD B1 & 1 & 1 \\
\hline $4-6$ & 2 & 2 \\
\hline $11-14$ & 2 & 1 \\
\hline $17-18$ & \multicolumn{2}{|l|}{} \\
\hline ULD B2 & 1 & 1 \\
\hline $19-23$ & 2 & 2 \\
\hline $26-28$ & 2 & 1 \\
\hline $9-10$ & 1 & 1 \\
\hline ULD B 3 & 1 & 1 \\
\hline $24-25$ & 2 & 2 \\
\hline $29-31$ & \multicolumn{2}{|l}{} \\
\hline $32-40$ & \multicolumn{1}{|l|}{} \\
\hline
\end{tabular}

According to the above loading scheme, the utilization rate of the cargo hold was calculated, and the result is shown in Figure 2.

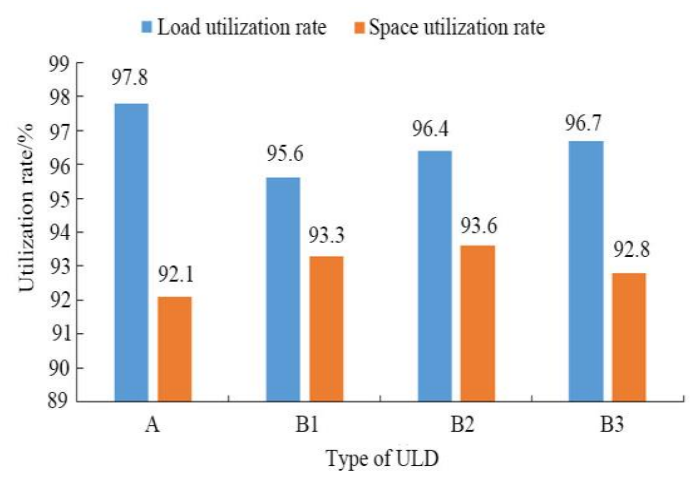

Figure 2: Cargo Hold Utilization

It was seen from Figure 2 that the load utilization rate of the loading scheme obtained by the algorithm proposed in this study was above $95 \%$, and the space utilization rate was more than $90 \%$. After calculation, the average load utilization rate of ULD was $96.63 \%$, and the average space utilization rate was $92.95 \%$. The algorithm proposed in this study was compared with the simulated annealing algorithm and genetic algorithm, and the results are shown in Table 5 .
Table 5. Performance Comparison of Different Algorithms

\begin{tabular}{|l|l|l|l|}
\hline & $\begin{array}{l}\text { Simulated } \\
\text { annealing } \\
\text { algorithm }\end{array}$ & $\begin{array}{l}\text { Genetic } \\
\text { algorithm }\end{array}$ & $\begin{array}{l}\text { The } \\
\text { algorithm } \\
\text { proposed } \\
\text { in this } \\
\text { study }\end{array}$ \\
\hline $\begin{array}{l}\text { Load } \\
\text { utilization } \\
\text { rate/\% }\end{array}$ & 91.68 & 93.21 & 96.63 \\
\hline $\begin{array}{l}\text { Space } \\
\text { utilization } \\
\text { rate/\% }\end{array}$ & 87.24 & 89.33 & 92.95 \\
\hline $\begin{array}{l}\text { Calculation } \\
\text { time/s }\end{array}$ & 978 & 256 & 56.78 \\
\hline
\end{tabular}

It was seen from Table 5 that the load utilization rate of the algorithm proposed in this study was $5.4 \%$ and $3.7 \%$ higher than the other two algorithms, and its space utilization rate was $6.5 \%$ and $4.1 \%$ higher, respectively, which showed that the loading scheme obtained by the algorithm proposed in this study was more excellent. In the aspect of the calculation time, it was found that only the algorithm proposed in this study was shorter than $100 \mathrm{~s}$, and the other two algorithms needed a long time to get the results. Overall, the algorithm proposed in this study had a better performance in loading optimization.

\section{Discussion}

With the development of e-commerce, logistics and aviation are more closely linked. The booming e-commerce enterprises have brought a broad market for aviation logistics, promoting the continuous progress of aviation logistics, and its demand is also growing [14]. In e-commerce logistics, to maximize the advantages of aviation logistics, it is necessary to improve transportation timeliness as much as possible, ensure the safety of goods, and reduce costs. At present, research on aviation logistics includes ground distribution path planning, freight forwarding, airport management, etc. [15], but research on loading optimization is relatively few.

In this study, the optimization model of freight loading was solved by the improved genetic algorithm. The analysis results of the example found that the loading scheme obtained by the algorithm had a $96.63 \%$ load utilization rate and a $92.95 \%$ space utilization rate; compared with the other two algorithms, the utilization rate of the algorithm proposed in this study was significantly higher, which showed that that scheme was more reasonable for cargo loading arrangement and made full use of space. 
The comparison of the calculation time also found that the algorithm proposed in this study needed less operation time, i.e., it could get a better scheme faster; therefore, it had a better performance in loading optimization.

The loading optimization problem is a key point of aviation logistics. In the future development, to achieve better loading optimization, in addition to obtain a better loading scheme using the model designed in this study, we can also:

(1) separate business flow from logistics: ecommerce enterprises should integrate the freight information, and then the airlines should carry out unified loading to improve the loading efficiency and the capacity of ground transportation;

(2) establish a perfect logistics information system to effectively and accurately transfer information;

(3) establish freight centers according to the freight volume of local e-commerce enterprises to reduce the cost of road transshipment.

\section{Conclusion}

In this study, a loading optimization model was designed and solved using an improved genetic algorithm. Then, in the analysis of the example, the comparison with the other two algorithms that the method obtained by the algorithm proposed in this study had a better utilization rate, shorter calculation time, and better performance in solving the loading optimization problem, which can be further promoted and applied in practice.

\section{References}

[1] Ha H T H, Nananukul N. "Air Cargo Optimization Models for Logistics Forwarders," Advanced Science Letters, 2017, 23(5):4162-4167(6)

[2] Chu Y L, Gong Z G, Yang Z Z. "The Spatial Pattern of China Air Cargo Transportation in $21 \sim(\mathrm{st})$ Century," Scientia Geographica Sinica, 2016, 36(3):335-341.

[3] Ashwini R, Manoj E. "Review on Cargo Space Optimization Methodologies," International Journal of Computer Applications, 2017, 162(3):31-34.

[4] Kulak O, Genç A, Taner M E. "A decision making tool considering risk assessment of subcontracting agents for an air cargo shipment planning problem," Journal of Air Transport Management, 2018, 69:123-136.
[5] Peng Y, Wang P, Zhao X, Chen M, Zhang J, Zhang F. "A data-driven air cargo redistribution model based on multiple programming," International Journal of Modern Physics B, 2019, 33(17):1950176.

[6] Paquay C, Schyns M, Limbourg S. "A mixed integer programming formulation for the threedimensional bin packing problem deriving from an air cargo application," International Transactions in Operational Research, 2016, 23(1-2): 187-213.

[7] Roesener A G, Barnes J W. "An advanced tabu search approach to the airlift loading problem," Logs Research, 2016, 9(1):1-18.

[8] Nance R L, Moore A R. "Special Issue: Heuristic Optimisation || An advanced tabu search for solving the mixed payload airlift loading problem," Journal of the Operational Research Society, 2011, 62(2):337-347.

[9] Liu Y T, Yang Z B, Deng J X, Zhu J J. "Investigation of fuel savings for an aircraft due to optimization of the center of gravity," Materials Science \& Engineering Conference Series, 2018.

[10] Bookbinder J H, Elhedhli S, Li Z. "The air-cargo consolidation problem with pivot weight: Models and solution methods," Computers \& Operations Research, 2015, 59(jul.):22-32.

[11] Zhang C, Xie F, Huang K, Wu T, Liang Z. "MIP models and a hybrid method for the capacitated air-cargo network planning and scheduling problems," Transportation Research Part E: Logs and Transportation Review, 2017, 103(jul.):158-173.

[12] Volkanovski A, Mavko B, Boševski T, Chaushevski A, Čepin M. "Genetic algorithm optimisation of the maintenance scheduling of generating units in a power system," Reliability Engineering \& System Safety, 2017, 93(6):779789.

[13] Zhang H, Lennox B, Goulding PR, Leung AYT. "A float-encoded genetic algorithm technique for integrated optimization of piezoelectric actuator and sensor placement and feedback gains," Smart Materials \& Structures, 2016, 9(4):552.

[14] Ross J. "Airfreight awakenings," American Shipper, 2017, 59(12):11-11.

[15] Budiarto S, Putro H P, Pradono P, Yudoko G. "Revenue management of air cargo service in theory and practice," IoP Conference, 2018, 158:012022. 